\title{
Stored Intracardiac Electrograms Reveal Patients With Sick Sinus Syndrome Frequently Develop Atrioventricular Block
}

\author{
Mikiko Nakagawa, MD, PhD
}

$\mathbf{S}$ ick sinus syndrome (SSS) is common but poorly understood and the only treatment is implantation of a pacemaker. ${ }^{1,2}$ In patients with SSS, AAI pacing mode has been recommended as a physiological pacemaker system. However, retrospective analysis has shown that some patients with SSS develop high-grade atrioventricular block (AVB) and need a pacemaker mode change from AAI to ventricular or dual-chamber pacing. ${ }^{3-6}$ Therefore, in the 1980 s dual-chamber pacing instead of a single chamber atrial pacing (AAI) was recommended in patients with SSS. Brandt et al reported highgrade AVB occurred in $8.5 \%$ (1.8\% per year) and its incidence was greater in patients with complete bundle-branch block or bifascicular block than in patients without such disturbances (35\% vs. $6 \%),{ }^{7}$ suggesting increased risk of subsequent AVB.

\section{Article p 1263}

On the other hand, Rosenqvist and Obel reviewed data from 28 studies, showing that a median annual incidence of highgrade AVB was $0.6 \%$ among patients with atrial pacing for SSS. ${ }^{8}$ Andersen et $\mathrm{al}^{9}$ performed a prospective study to evaluate the AV conduction and the risk of developing AVB during long-term follow-up (mean $5.5 \pm 2.4$ years) of patients with SSS. There was no change in AV conduction and only a few patients developed high-grade AVB (0.6\% per year). However, the presence of bundle-branch block was associated with such a risk. Those results indicated that patients with SSS have a low risk of developing high-grade AVB (0.6-1.8\% per year) and dual-chamber pacing was recommended as the primary choice especially for patients with complete bundle-branch block or bifascicular block at the time of implantation.

In the previous studies, the incidents of AVB included asymptomatic episodes detected on a few Holter ECG recordings or only symptomatic episodes such as dizziness or syncope. Therefore, the real number of AVB episodes during the entire follow-up period in the patients with SSS has not been evaluated. In recent years, new pacing modes have been developed, SafeR $^{\mathrm{TM}}$ (SORIN Group CRM SAS, Clamart, France) or managed ventricular pacing (MVP; Medtronic, Minneapolis, MN, USA), which were designed to combine the advantages of AAI with the safety of DDD mode. ${ }^{10,11}$ These pacing modes decrease the frequency of ventricular pacing compared with DDD mode. SafeR mode can automatically detect and store the intracardiac electrograms (EGM) of AVB episodes during the entire follow-up period.

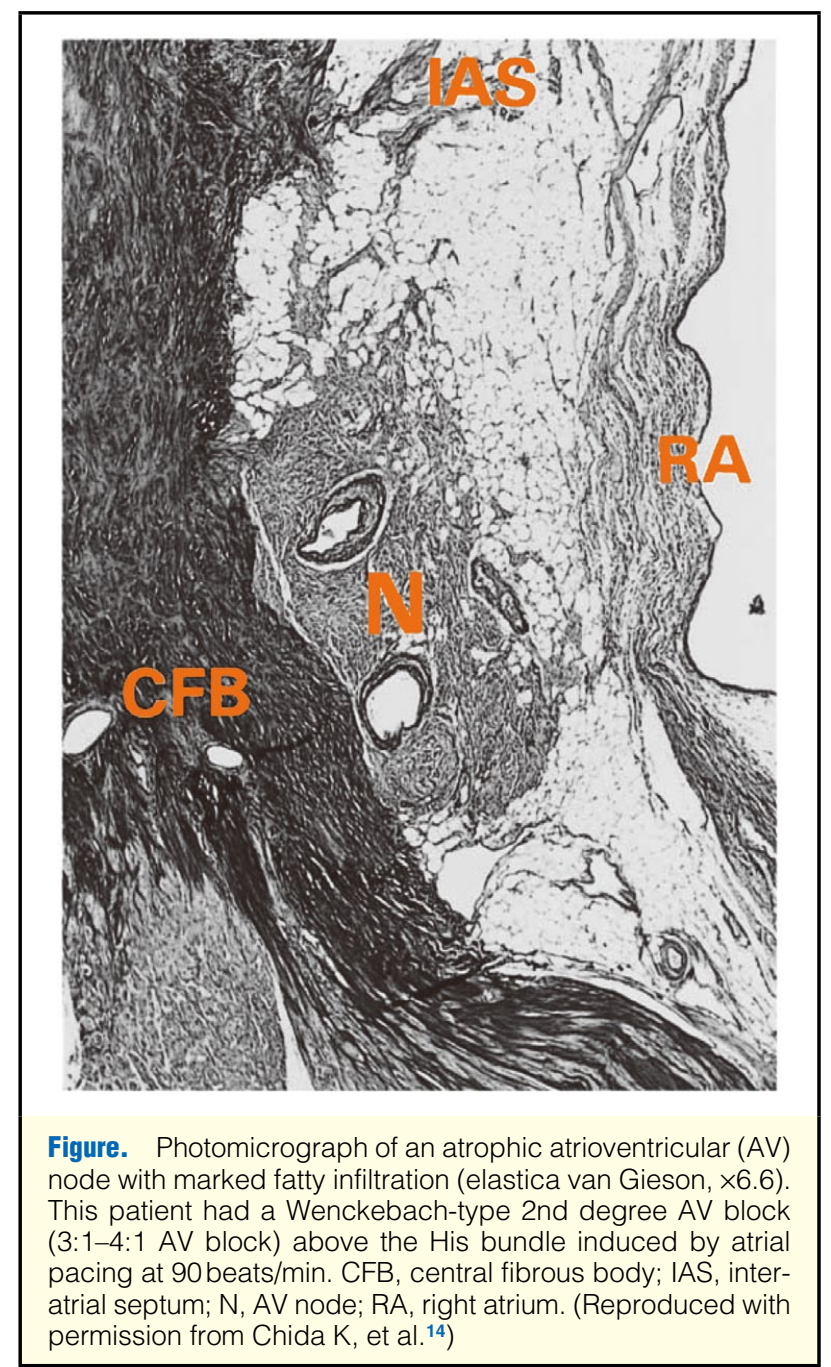

In this issue of the Journal, Hosoda et al ${ }^{12}$ analyze AVB episodes based on the stored EGM in a cardiovascular implantable electronic device mounting the SafeR mode, and determine the occurrence rate and risk factors for advanced AVB in patients with SSS. In their study, the mean percentage of ven-

The opinions expressed in this article are not necessarily those of the editors or of the Japanese Circulation Society.

Received April 20, 2015; accepted April 20, 2015; released online May 1, 2015

Medical Education Center, Faculty of Medicine, Oita University, Yufu, Japan

Mailing address: Mikiko Nakagawa, MD, PhD, Medical Education Center, Faculty of Medicine, Oita University, 1-1 Idaigaoka, Yufu 879-5593, Japan. E-mail: mikinak@ oita-u.ac.jp

ISSN-1346-9843 doi:10.1253/circj.CJ-15-0446

All rights are reserved to the Japanese Circulation Society. For permissions, please e-mail: cj@j-circ.or.jp 
tricular pacing was only $2.5 \pm 8.1 \%$, which was low enough to detect most of the AVB events. The stored EMGs were carefully reviewed by physicians and 73 of 377 EGMs (19.4\%) were determined as advanced AVB episodes. Advanced AVB occurred in 9 of 50 patients (18\%), and the occurrence rate of advanced AVB was $11.7 \%$ per year, which was much higher than in previous studies (0.6-1.8\% per year). In addition, multivariate analysis revealed that $\beta$-blocker use was an independent risk factor for advanced AVB. However, the occurrence rate of advanced AVB in patients without $\beta$-blockers was $7.8 \%$ per year, which was also higher than in previous reports. Thus, the authors conclude that patients with SSS have an increased risk of advanced AVB irrespective of $\beta$-blocker treatment, and suggest the use of a dual-chamber pacemaker rather than a single-chamber atrial pacemaker. Although bundle-branch block and the Wenckebach block rate were not associated with advanced AVB in their analysis, previous reports suggested that the presence of bundle-branch block or lower Wenckebach block rate $(<120$ beats/min $)$ were high risks of the development of AVB. ${ }^{7,9}$

Previous histological examination revealed widespread fibrosis in the AV conduction system of patients with SSS. ${ }^{13}$ Chida et $\mathrm{al}^{14}$ studied the histopathological findings of the AV conduction system in 14 elderly patients treated with pacemakers for SSS. The patients who had a Wenckebach block point $<130$ beats/min showed excessive fatty infiltration around the atrionodal junction area and into the atrophic AV node (Figure). Most of the remaining cases also had an atrophic AVN. The results from Hosoda et $\mathrm{al}^{12}$ agree with histopathological studies that suggested sinus node dysfunction is often the clinically apparent manifestation of a widespread degenerative process in the cardiac conduction system.

In conclusion, it is important to be reminded of an increased risk of high-grade AVB in patients with SSS, especially the elderly or $\beta$-blocker users.

\section{References}

1. Morris GM, Kalman JM. Fibrosis, electrics and genetics: Perspec- tives in sinoatrial node disease. Circ J 2014; 78: 1272-1282.

2. JCS Joint Working Group. Guidelines for non-pharmacotherapy of cardiac arrhythmias (JCS 2011): Digest version. Circ J 2013; 77: 249-274.

3. Breivik K, Ohm OJ, Segadal L. Sick sinus syndrome treated with permanent pacemaker in 109 patients: A follow-up study. Acta Med Scand 1979; 206: 153-159.

4. Vallin H, Edhag O. Associated conduction disturbances in patients with symptomatic sinus node disease. Acta Med Scand 1981; 210: 263-270.

5. Bertholet M, Demoulin JC, Fourny J, Kulbertus H. Natural evolution of atrioventricular conduction in patients with sick sinus syndrome treated by atrial demand pacing: A study of 26 cases. Acta Cardiol 1983; 38: $227-232$.

6. Sutton R, Kenny RA. The natural history of sick sinus syndrome. Pacing Clin Electrophysiol 1986; 9: 1110-1114.

7. Brandt J, Anderson H, Fåhraeus T, Schüller H. Natural history of sinus node disease treated with atrial pacing in 213 patients: Implications for selection of stimulation mode. J Am Coll Cardiol 1992; 20: $633-639$.

8. Rosenqvist M, Obel IW. Atrial pacing and the risk for AV block: Is there a time for change in attitude? Pacing Clin Electrophysiol 1989; 12: $97-101$.

9. Andersen HR, Nielsen JC, Thomsen PE, Thuesen L, Vesterlund T, Pedersen AK, et al. Atrioventricular conduction during long-term follow-up of patients with sick sinus syndrome. Circulation 1998; 98: $1315-1321$.

10. Savoure A, Frohlig G, Galley D, Defaye P, Reuter S, Mabo P, et al. A new dual-chamber pacing mode to minimize ventricular pacing. Pacing Clin Electrophysiol 2005; 28: S43-S46.

11. Frohlig G, Gras D, Victor J, Mabo P, Galley D, Savoure A, et al. Use of a new cardiac pacing mode designed to eliminate unnecessary ventricular pacing. Europace 2006; 8: 96-101.

12. Hosoda J, Ishikawa T, Sumita S, Matsushita K, Matsumoto K, Kimura Y, et al. Development of atrioventricular block and diagnostic value of stored electrocardiograms in patients with sick sinus syndrome and implanted pacemaker. Circ J 2015; 79: 1263-1268.

13. Demoulin JC, Kulbertus HE. Histopathological correlates of sinoatrial disease. Br Heart J 1978; 40: 1384-1389.

14. Chida K, Imai T, Taniguchi T, Maeda S, Watanabe C, Esaki Y, et al. Implications of marked fatty infiltration around and in the atrophic atrioventricular node in elderly patients with permanent pacemaker implantation for symptomatic sick sinus syndrome. Jpn Circ J 1999; 63: $343-349$. 